\title{
HALOCLINE CATASTROPHES, SEA ICE, AND OCEAN CLIMATE (Abstract)
}

\author{
by
}

Knut Aagaard

(NOAA/PMEL/MSRD, 7600 Sand Point Way N.E., Seattle, WA 98115, U.S.A.)

Rapid melting of continental ice during deglaciations has been hypothesized to shift the thermohaline circulation of the world ocean to a mode radically different from the one dominated by the North Atlantic, such as operates today. This scenario has been referred to as the halocline catastrophe. We consider here the freezing, transport, and melting of sea ice in the North Atlantic sector as a possible modern analog to such events.

The rejection of salt during the freezing and subsequent development of sea ice results, by early summer, in ice with only $5-10 \%$ of its original salt content. Since sea ice several meters thick is typically formed annually in the polar regions, the distillation rates from freezing are fully comparable to those from evaporation in such highly evaporative basins as the Red Sea. If the ice is subsequently exported from its production area, then freezing and melting are the oceanic equivalent of the hydrologic cycle. In the Arctic, the major ice outflow from the $10^{7} \mathrm{~km}^{2}$ of the Polar Basin occurs east of Greenland, where the exodus represents a fresh-water transport of at least $2800 \mathrm{~km}^{3} \mathrm{a}^{-1}$. This is a discharge more than twice that of North America's four largest rivers combined.

The fresh water can subsequently be traced around the subpolar gyre of the North Atlantic, on its way transferring small but significant amounts of buoyancy into the interior convective gyres, e.g. in the Greenland Sea. The convection which occurs in these gyres under present climatic conditions makes them major ventilation and water mass formation sites for the deep world ocean, but because the density of sea water at constant pressure and low temperature is almost solely dependent on salinity, the convection is extremely sensitive to changes in the freshwater supply to the gyres. Small variations in the supply will be transferred into the deep ocean by convection, where they will be manifested by a cooling and freshening, such as has recently been observed in the deep North Atlantic. However, if the surface layers are freshened too much, cooling even to the freezing point will be insufficient to initiate convection. Instead, the convective gyres will be capped by a fresh-water lid, essentially what has been proposed in the halocline catastrophe scenarios. During such events, sea ice will form in the gyres, sometimes with disastrous consequences, as occurred north of Iceland during the late 1960 s when, during the extreme years of 1965 and 1968, the entire north and east coasts of Iceland were enveloped by sea ice; at the same time renewal to the north of the deep ocean waters diminished or ceased.

We suggest that the present-day Greenland and Iceland seas, and probably also the Labrador Sea, are rather delicately poised with respect to their ability to sustain convection, and that we have in fact during the past several decades seen a small-scale analog to the halocline catastrophe proposed for past deglaciations. A major difference is that the present situation does not require dramatic increases in fresh-water flux to effect a capping of the convection; nor does it depend on deglaciation. Rather, very modest changes in the disposition of the fresh water presently carried by the East Greenland Current can alter or stop the convection; and the principal source of fresh water is sea ice, rather than glacial ice. The essence of the present situation is that the large fresh-water output from the Arctic Ocean, which is the distillate of freezing, passes perilously close to the very weakly stratified convective gyres; and that the stratification in these gyres is easily perturbed, either by variations in the discharge from the Arctic Ocean or by leaks or recirculation from the boundary current. 